\title{
Deterioration Factor analysis of Composite Insulators based on Experiment and Mathematical Statistics
}

\author{
ZHENG Weigang $^{1, a}$, , ZHU Yidong ${ }^{1, b}$, LIU Wenjuan ${ }^{2, c}$,WANG Lulu ${ }^{3, d}$, WANG \\ $\mathrm{Fei}^{1, \mathrm{e}}$
}

${ }^{1}$ Electric Power Research Institute of Liaoning province electric power Co. Ltd. Shenyang, China;

\author{
${ }^{2}$ Liaoning Province Electric power Co. Ltd. Shenyang, China \\ ${ }^{3}$ Yingkou Power Supply Company. Yingkou, China \\ A67812094@qq.com, b13842058010@qq.com, 'Iwj@In.sgcc.com.cn dwll@In.sgcc.com.cn, \\ ewf@In.sgcc.com.cn
}

\begin{abstract}
Keywords: Composite insulators, deterioration factor, statistics, elemental analysis
Abstract. The electrical performance and mechanical properties of nearly 200 composite insulators operating in the power grid for over 5 years are tested, to grasp the current running state of composite insulators, While statistical analysis of their regional type, age, process and so on,the correlation between the degradation of the composite insulators and the boundary conditions is obtained by means of experimental results and statistical methods.
\end{abstract}

\section{Introduction}

In recent years, the composite insulator damage is also increasing, there will be a serious fall on, brittle fracture and so on, therefore, to test and statistical analysis of the composite insulator deterioration factors necessary to systematically. In view of this, for the operation condition of composite insulators in system, according to the differences of the composite insulator in different period of structure, formula, process, manufacturing level, operating conditions, and combined with the operating environment, operation time, different geographical environment, in the typical areas the composite insulators are sampled on a large scale, this article focuses on the research on the operation performance of electrical, mechanical and degradation of composite insulator and service life evaluation methods. Based on the test results and data analysis, especially the key factors on the basis of analyzing and influencing safe and reliable operation of composite insulators, the method of evaluating the aging performance of ac and dc composite insulators is put forward.

\section{Sampling Extraction for Running Composite Insulator}

The section headings are in boldface capital and lowercase letters. Second level headings are typed as part of the succeeding paragraph (like the subsection heading of this paragraph). Based on the deterioration analysis of influencing composite insulator, it is in need to take full consideration of the deterioration state of composite insulator, include running time, electric field distribution, manufacturing process, running external environment and so on, and try to make the number of samples larger, full coverage of the type.

In this paper, the deterioration analysis method research on main factors of sampling plan is given in the table 1. 
Table 1 Main factors of sampling plan

\begin{tabular}{|c|c|c|}
\hline Running life & Technological formula & $\begin{array}{l}\text { Manufacturing } \\
\text { enterprise }\end{array}$ \\
\hline $\begin{array}{l}\text { It is divided into three } \\
\text { sections according to the } \\
\text { service life. } \\
\text { First, composite insulators } \\
\text { at service between } 5 \text { years } \\
\text { to } 8 \text { years ( } 66 \mathrm{kV} \text { 、 } \\
220 \mathrm{kV} 、 500 \mathrm{kV} \text { ) } \\
\text { Second, composite } \\
\text { insulators at service } \\
\text { between } 8 \text { years to } 15 \text { years } \\
\text { ( 66kV } 220 \mathrm{kV}) \\
\text { Third, composite insulators } \\
\text { at service more than } 15 \\
\text { years. }(66 \mathrm{kV} 、 220 \mathrm{kV})\end{array}$ & $\begin{array}{l}\text { First, } 1995 \text { and early: Extrusion and } \\
\text { irrigation technology is gradually } \\
\text { eliminated. } \\
\text { Second, from } 1995 \text { to } 20000 \text { years: The } \\
\text { technology of end connection, forming } \\
\text { process and sealing process is improved. } \\
\text { More accidents. } \\
\text { Third, from } 2001 \text { to } 2005 \text { :The } \\
\text { continuous improvement of technology, } \\
\text { technical knowledge gradually unified. } \\
\text { Fourth: The implementation of } \\
\text { centralized bidding, market competition } \\
\text { is becoming increasingly fierce, prices } \\
\text { continued to decline. }\end{array}$ & $\begin{array}{l}\text { Xiangfan Guowang } \\
\text { Shandong Taiguang } \\
\text { Xiangyang Electric } \\
\text { Power } \\
\text { Guangzhou MPC } \\
\text { electric power Co., } \\
\text { Ltd ( MPC) } \\
\text { Baoding Electric } \\
\text { Power Equipment } \\
\text { Manufacturing Co., } \\
\text { Ltd (BD ) }\end{array}$ \\
\hline
\end{tabular}

According to above sampling plan, follow-up a total of 195 composite insulators are extracted, which are as shown in the following table, according to the voltage level, the operating life, manufacturing enterprises.

Table 2 Sampling on $66 \mathrm{kV}$ composite insulators

\begin{tabular}{|c|c|c|c|c|c|}
\hline Service years & MPC & TG & XF & Other & Subtotal \\
\hline 5-8 years & 14 & 12 & 10 & 8 & 36 \\
\hline 8-15years & & & 18 & 6 & 18 \\
\hline More than 15 years & & & 6 & 5 & 11 \\
\hline Total & 14 & 12 & 34 & & 79 \\
\hline
\end{tabular}

Table 3 Sampling on 220kV composite insulators

\begin{tabular}{|c|c|c|c|c|c|c|c|}
\hline Service years & TG & XF & XY & HNF & BD & Other & Subtotal \\
\hline 5-8 years & 12 & & & & & 2 & 14 \\
\hline 8-15years & & 24 & 6 & 8 & 8 & 3 & 49 \\
\hline More than15years & & & 6 & & & 2 & 8 \\
\hline Total & & & & & & & 71 \\
\hline
\end{tabular}

Table 4 Sampling on 500kV composite insulators

\begin{tabular}{|l|l|l|l|l|}
\hline Service years & MPC & TG & Other & Subtotal \\
\hline $5-8$ years & & 12 & 5 & 17 \\
\hline $8-15$ years & 24 & & 4 & 28 \\
\hline Total & & & & 45 \\
\hline
\end{tabular}

This focus sampling covers the voltage class $66 \mathrm{kV}, 220 \mathrm{kV}, 500 \mathrm{kV}$ of composite insulators at service; composite insulators at service between five years and eight years accounting for $38.4 \%$, between eight years and fifteen years accounting for 51.8\%, more than 15 years accounting for $9.8 \%$. This paper covers the typical manufacturing stage of domestic composite insulators.

In the operating environment, the general dirty areas, dust pollution areas, coastal pollution areas are selected. In the structure process, the early insulator is umbrella structure, the mandrel is non-acid core rod, after 2000, the insulator is mainly for the whole concreting technology. 


\section{Analysis and Process of Experimental Data for Running Composite Insulator}

Experimental Standard. The test items are carried out by the following criteria:

--"Guide for the use of composite insulators for AC overhead lines with a nominal voltage above 1000V".

--“Composite insulators for AC overhead lines with a nominal voltage above 1000V - Definitions, test methods and acceptance criteria".

Experimental Quantity. The appearance and hydrophobicity of all sampling composite insulators are measured, and the measurement of contamination degree, boiling test, steep wave impulse voltage test, interface permeability test and mechanical failure test are carried out in proportion. The number of insulators tested in each experiment item is as follows:

Table 5 Experimental quantity table

\begin{tabular}{|l|l|l|l|}
\hline Experiment items & $66 \mathrm{kV}$ & $220 \mathrm{kV}$ & $500 \mathrm{kV}$ \\
\hline Appearance & 79 & 71 & 45 \\
\hline Hydrophobicity & 79 & 71 & 28 \\
\hline Pollution grade & 40 & 38 & 18 \\
\hline Steep wave & 14 & 16 & 6 \\
\hline Mechanical failure & 24 & 12 & 6 \\
\hline
\end{tabular}

Summary of experimental results. Summary of experimental results are as follows:

A. appearance inspection

The surface of the majority sampling insulators is good, and there are some problems in the damage and brittleness of the minor umbrella skirt. There are in all 8 insulators existing appearance problems, among them, there are two insulators service times between 5 and 8 years, four insulators service time between 8 and 15 years, two insulators service times more than 15 years, there is no significant correlation between the tearing of umbrella group and the contamination test, from the destruction appearance, the insulator umbrella skirt damage within 8 years is mainly caused by mechanical force, such as construction stampede, transport extrusion, etc., which does not belong to the normal deterioration defects, and more than 15 years, from the cross-section and umbrella skirt which is brittle and hardness, it is caused by deterioration.

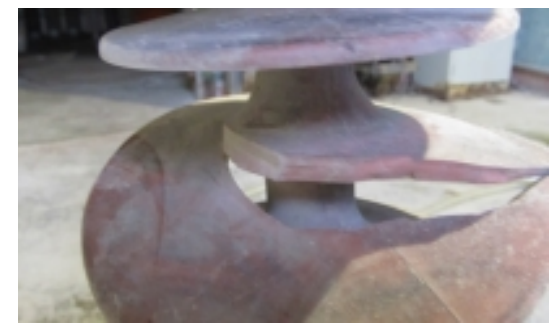

Fig.1 Damage and brittleness of insulator umbrella skirt

B. pollution grade measurement and hydrophobicity analysis

Measurement results of salt density of composite insulators are between $0.09 \mathrm{mg} / \mathrm{cm} 2$ and $0.48 \mathrm{mg} / \mathrm{cm} 2$. Part of the insulator pollution is very serious, most of the area is covered by cement scaling, as is shown in figure 2.And it is found that the insulator at long service is obvious slightly higher in whole pollution grade than the insulator at short service. 


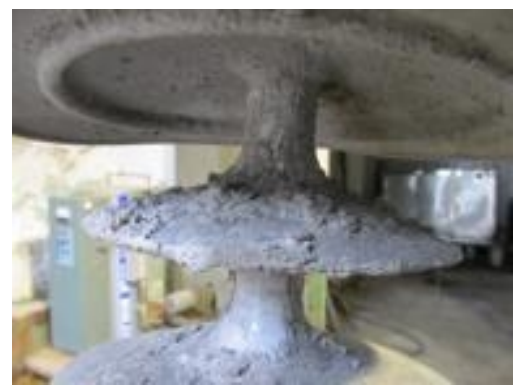

Fig.2 Insulator contamination situation

Table 6 Test results of average contamination (maintenance-free)

\begin{tabular}{|c|c|c|c|}
\hline Experiment items & $5-8$ years & $8-15$ years & More than15 years \\
\hline Pollution grade & 0.11 & 0.15 & 0.16 \\
\hline Hydrophobicity & whole & whole & Whole HC5 \\
\hline & HC3 & HC3-4 & \\
\hline
\end{tabular}

From the test results, the areas located in severe cement, fused magnesium dust pollution, the hydrophobicity of umbrella skirt is decline more obvious than it in the coastal area, lower 1-2 level. The sampling insulation surface hydrophobic distribution of the voltage level is between HC2 and HC5.

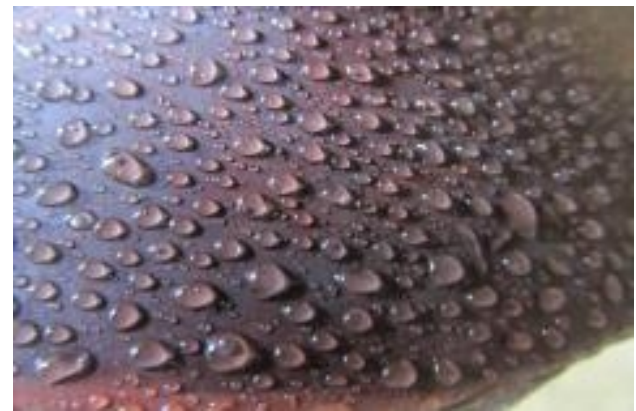

a) Good hydrophobicity

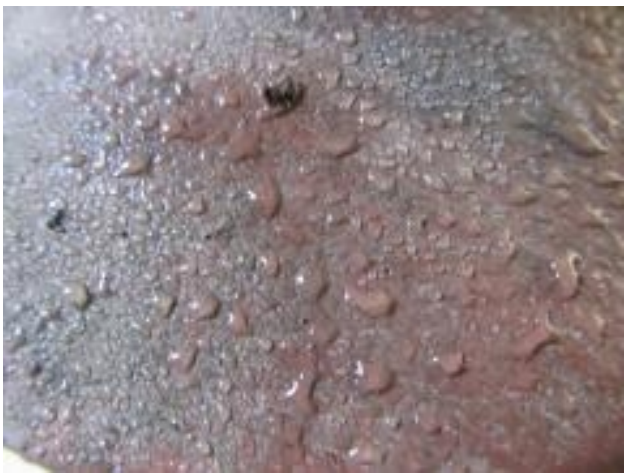

b) Poor hydrophobicity

Fig.3 Hydrophobicity of insulators

\section{Steep wave impact experiment}

There are total 36 insulators, which are tested by steep wave impulse experiment, wave steepness is about $1200 \mathrm{kV} / \mu \mathrm{S}$, there is no insulation internal breakdown occurred during the test. Two upper and lower are respectively selected to carry out positive and negative steep wave on $66 \mathrm{kV}$ insulator, three parts are selected to carry out positive and negative steep wave impact test on $220 \mathrm{kV}$ insulator and $500 \mathrm{kV}$ insulator. There is no interface or insulation internal breakdown in insulator experiment.

D. Mechanical damage load experiment

There are 42 insulators of $66 \mathrm{kV}, 220 \mathrm{kV}$ and $500 \mathrm{kV}$ tested on mechanical damage load test, and a small number of insulators are carried on permeability experiment.

From the operation data and tests, it is found that some gold and mandrel of manufacturers with the wedge crimp structure insulator, which is less than the rated tensile fracture situation, it reflects close relation between the structure and mechanical load . 

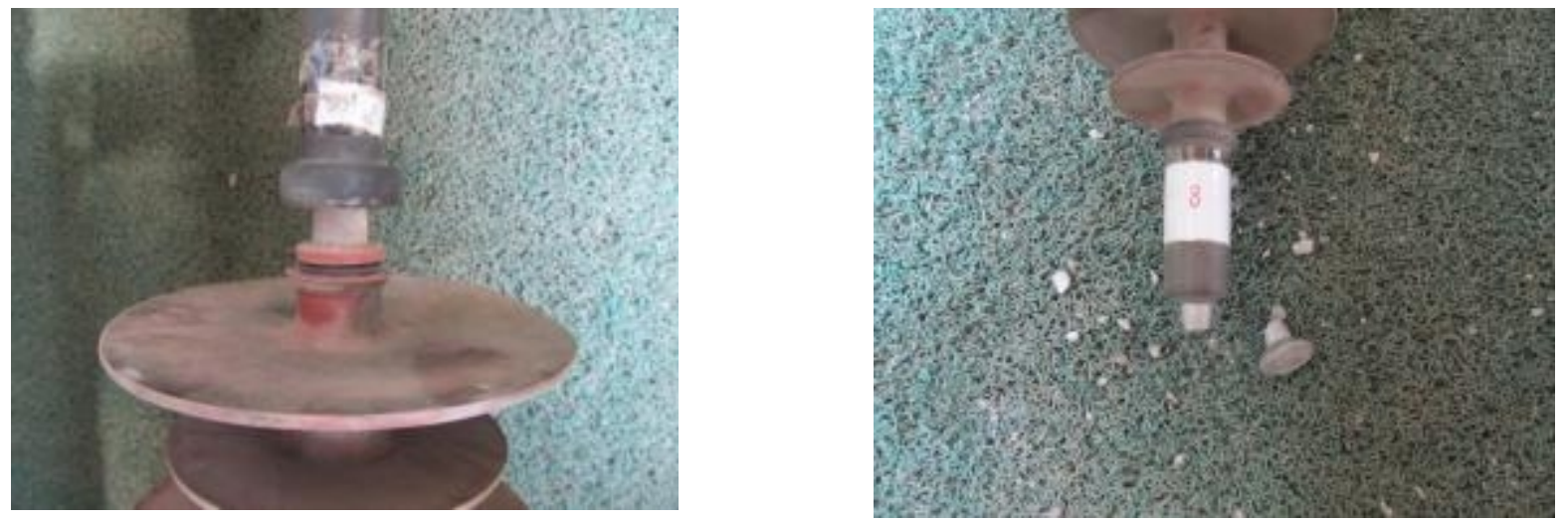

Fig.4 Mechanical disruption of insulators

\section{Analysis of Deterioration Factors}

Operating Environment. For the same being operated years and same batch insulators, there are sizable difference on the umbrella cover degradation, pollution performance, and the performance of shed material. Among, the hydrophobicity, hardness, tensile elongation changed obviously, while the tear strength, tensile strength are less affected.

Power Grid Cycle Factors. According to the experimental conclusion and statistics, the insulators at service more than 15 years is significantly worse than shorter operation of the insulator, mainly with the increase of operating age, as well as the time of electric field stress, mechanical stress and environmental stress on the insulator also will increase, thus the resulting accumulation will further affect the various properties of insulator.

The hydrophobicity of insulator has great relation to the formulations, manufacturing processes, voltage class, operating environment, etc. the hydrophobicity of operating composite insulator is not significantly associated with the change of operating years, but with material formulations and operating environment more.

With the increase of operating years, the tensile elongation of insulator has shown a descending trend, the changes of the hardness, tear strength, tensile strength are not obvious.

Analysis of manufacturing process and material formulation. For same transmission lines, same operating years of insulator umbrella cover material in typical area, the experiment results show that the insulators of early formulations are most pulverization and hardened, but the hydrophobicity can still be achieved HC2-HC4,part of the insulators the sclerosis is serious and hydrophobic loss, the minority insulators are not hardened, powdered, and that better hydrophobicity.

Design, manufacture and selection. A great deal of operational accidents analysis indicates that defects of products design, poor selection of raw materials and components, loopholes of manufacturing management, unreasonable selection and so forth will cause the insulator abnormal aging and premature failure.

For instance, composite insulators causing operation accidents have defects as follows:

(1) Mandrel quality: Early products due to the quality of the mandrel lead to mandrel breakdown.

(2) Interphase connection: the improper handling between mandrel and the interphases of umbrella cover, or the leakage of individual products interphases aren't dealt with as a result of poor management, or air gap between mandrel and the interphases of umbrella cover causes interphase breakdown.

(3)Sealing failure: sealing by room temperature vulcanized silicone rubber or the design of seal structure unreliable, leading to moisture into the interface, resulting in irreversible breakdown or brittle fracture due to corrosion mandrels. 
(4) Mechanical connection: in the early stage, internal wedge type, external wedge type, internal and external wedge type and adhesive type terminal connection process has defects and crimping process control is not accurate enough.

(5) Decline of the hydrophobicity: low content of silicone rubber, the unreasonable process formula, the deposition of dunghill, loss of small molecular weight (LMW) in silicone rubber and other factors leading to the decline in hydrophobicity and migration performance.

(6)Pressure-equalizing device: the unreasonable design and processing of pressure-equalizing device, so it cannot protect terminal connection area of the metal accessories well, will also make the radio interference level does not satisfy the service requirements; improper use, such as install or reverse assembling pressure device out of accordance with specified quantity.

\section{Conclusions}

In this paper, the deterioration factors of insulators are analyzed one by one by means of experimental data and multivariate statistical analysis. the running time, operating environment and manufacturing process are the important factors influencing the deterioration.

The shed materials performance of operating composite insulator declines in various degrees with time, which mainly reflects in hydrophobicity, hardness, mechanical tensile strength parameters. For the majority of insulators, there is no significant decrease in mechanical properties, with no interface connection defects.

The major factors that affect the operating performance and aging characteristics of composite insulators include: the operating environment, the technological formula, the influence rule of operating years is not obvious, the unreasonable design, manufacture and unreasonable use can also lead to the improper aging and premature failure of insulators.

Suggesting the average service life of domestic insulator is about 20 years under the normal design, normal manufacture, normal service and maintenance, after 10 years of operating, we should increase the sampling inspection efforts, the main way is sampling appearance, hydrophobicity, whether or not there is a hole defect in the skirt embrittlement degree etc.

\section{Acknowledgements}

This work was financially supported by State Grid Liaoning Electric Power Co., Ltd. science and technology project: Study on aging characteristics of composite insulators.

\section{References}

[1] Muhammad AMIN, Muhammad AKBAR, Muhammad SALMAN. Composite insulators and their aging: An overview, Science in China (Series E: Technological Sciences), pp.697-713, vol. 50 ,no. 6, 2007.

[2] YE Tinglu, WU Guangya, ZHANG Aijun. Composite Insulator operation performance and service life assessment method research, Annual meeting of power transmission and transformation 2012,Shanghai, China, September, 2012. pp.320-326

[3] YANG Ting, ZHANG Benhuang, LI Hengzhen, LIU Gang. The study on the aging of composite insulators operating for different years in Dongguan area, 2010 3rd International Conference on Power Electronics and Intelligent Transportation System, Shenzhen, China, November 13-14, 2010. 272-275 